\title{
Terapi Senam Otak untuk Menstimulasi Kemampuan Memori Jangka Pendek pada Anak Autis
}

\author{
Dinie Ratri Desiningrum ${ }^{1}$ \\ Fakultas Psikologi Universitas Diponegoro
}

\begin{abstract}
The aims of the research to stimulate short-term memory skills of children with autism through the therapy of brain gym performed using method of Quasi-Experimental, with one-group pretest-posttest design, on 10 children with autism in SLB ' $N$ ' Semarang. This research using module of brain gym with the audio-visual, and an evaluation sheet of Digit Span from Weschler . The study consisted of a pre-test, brain gym with 10 times treatment within 5 weeks, which is given by the method of IEP (Individualized Education Program), and the last is the post-test. Analysis of the data using the Wilcoxon test for pre-test and post-test two dependent samples. The result is significantly improved, with the score $Z=-2.023$ and a significance level of $0.043<0.05$. This means that brain gym which conducted regularly by children with autism have an effect to improving the ability of short-term memory.
\end{abstract}

Keywords: autism, brain gym, short term memory

Abstrak. Penelitian ini bertujuan untuk merangsang kemampuan memori jangka pendek dari anak autis melalui terapi senam otak yang dilakukan dengan menggunakan metode Quasi-Eksperimental, dengan One-Group Pretest-Posttest Design, pada 10 anak autis di SLB ' $\mathrm{N}$ ' Semarang. Penelitian ini menggunakan modul senam otak dengan audio visual, dan lembar evaluasi Digit Span dari Weschler. Penelitian ini terdiri dari pre-test, senam otak dengan pengobatan 10 kali dalam waktu 5 minggu, yang diberikan dengan metode (Program Pendidikan Individual) IEP, dan yang terakhir adalah post-test. Analisis data menggunakan uji Wilcoxon untuk pre-test dan post-test dua sampel dependen. Hasilnya meningkat secara signifikan, dengan skor $Z=-2,023$ dan tingkat signifikansi 0,043<0,05. Ini berarti bahwa senam otak yang dilakukan secara rutin oleh anak-anak dengan autisme memiliki efek untuk meningkatkan kemampuan memori jangka pendek.

Kata kunci: autis, memori jangka pendek, senam otak

Polusi yang melanda kota-kota besar di Indonesia telah banyak menimbulkan berbagai dampak negatif. Ragam penyakit mulai dari penyakit saluran pernapasan, kulit dan juga stres adalah dampak negatif dari polusi. Polusi juga dianggap sebagai penyebab menurunnya kecerdasan anak,

\footnotetext{
${ }^{1}$ Korespondensi mengenai isi artikel ini dapat dilakukan melalui: dn.psiundip@gmail.com
}

selain itu polusi juga diduga menimbulkan gangguan pertumbuhan pervasif yaitu autism (Budhiman, Shattock, \& Ariani, 2002). Pada dasarnya penyebab autisme adalah multifaktorial. Faktor genetik maupun lingkungan diduga mempunyai peranan yang signifikan. Sebuah studi mengemukakan bahwa apabila satu keluarga memiliki satu anak autis maka 
terdapat risiko untuk memiliki anak kedua dengan kelainan yang sama, namun lingkungan juga berpengaruh karena cukup banyak ditemukan salah satu anggota keluarga yang menderita autistik dengan kerusakan ringan dalam kemampuan sosial dan komunikasi atau mempunyai kebiasaan yang repetitif. Akan tetapi penyebab secara pasti belum dapat dibuktikan secara empiris (NINDS, 2006).

Secara umum autisme adalah gangguan perkembangan yang ditandai dengan perkembangan gangguan dalam komunikasi, interaksi sosial, dan perilaku. Lebih jauh terdapat penelitian yang mengukur kemampuan motorik dan bahasa terhadap 21 anak autis dengan speech delay dan 18 tanpa speech delay, dan ditemukan bahwa kemampuan bahasa awal berhubungan dengan kemampuan motorik sederhana dan kompleks pada individu dengan autism spektrum disorder (ASD)/ gangguan spektrum autisme (Barbeau, Meilleur, Zeffiro, \& Mottro, 2015).

Autisme menimpa satu dari sekitar 100 anak dan memengaruhi kehidupan baik anak itu sendiri maupun keluarga mereka. Di Indonesia menurut data yang ada terdapat kecenderungan autisme ini meningkat, merujuk pada prevalensi di dunia, saat ini terdapat 15-20 kasus per 10.000 anak atau $0,15 \%-0,20 \%$. Jika kelahiran di Indonesia enam juta per tahun maka jumlah penyandang autis di Indonesia bertambah $0,15 \%$ atau sekitar 6900 anak pertahun dengan perbandingan anak laki-laki tiga sampai empat lebih banyak dari anak perempuan. Semakin lama semakin banyak kasus gangguan autis. Pada tahun 1966, ditemukan 4,5 per 10.000 anak berumur sampai 8-10 tahun. Tahun 2002, mencapai 1 per 10.000 anak, bahkan laporan dari beberapa tempat menunjukkan angka 1 per 150 anak. Anak laki-laki 4-5 kali lebih sering dibandingkan perempuan. Setiap tahun, angka kejadian autisme meningkat pesat. Data terbaru dari Centre for Disease Control and Prevention tahun 2010 di Amerika Serikat menyebutkan, kini 1 dari 110 anak di sana menderita autis. Angka ini naik 57 persen dari data tahun 2002 yang memperkirakan angkanya 1 dibanding 150 anak (data autis di Indonesia, http://autismindonesia.org/).

Schechter dan Grether (2008) menganalisis data kasus-kasus autis anak pada California Departement of Developmental Service. Untuk setiap tahun yang berumur 3-12 tahun, estimasi prevalensi autis anak meningkat selama periode studi. Untuk anak lahir sebelum 1993, prevalensi autis pada umur tiga tahun adalah 0,3/1.000 anak. Tahun 2003, prevalensi autis anak umur tiga tahun adalah 1,3/1.000 anak. Prevalensi tertinggi terjadi tahun 2006, yaitu 4,5/1.000 anak lahir diperkirakan menderita autis. Walaupun terlalu dini untuk menghitung prevalensi untuk umur enam tahun atau lebih anak-anak yang dilahirkan setelah tahun 2.006, prevalensi pada umur 3-5 tahun telah meningkat setiap tahun sejak tahun 1.999. Berdasarkan gambaran kuartal, angka kasus autis pada umur 3-5 tahun meningkat setiap kuartal dari Januari 1995 (0,6 per 1.000 kelahiran hidup) sampai dengan maret 2007 (4,1 per 1.000 kelahiran hidup).

Orang tua biasanya tidak langsung memeriksakan anak dengan autis ke ahli kesehatan, orang tua cenderung menundanya dengan berbagai alasan. Suatu survei dari 1.047 orang tua dari anak autis menunjukkan bahwa orang tua biasanya menunggu satu tahun setelah adanya kekhawatiran tentang perkembangan anak mereka sebelum mereka mencari bantuan profesional. Rata-rata, ada penundaan sekitar 3,5 tahun, orang tua mulai mendekati seorang profesional kesehatan mengenai kejelasan diagnosis gangguan 
spektrum autisme. Hanya lebih dari setengah dari orang tua yang disurvei tidak puas dengan proses diagnostik secara keseluruhan (Crane, Chester, Goddard, Henry, \& Hill, 2015).

Orang tua dan para ilmuwan memiliki sikap dan keyakinan tertentu terkait dengan ASD. Hasil penelitian yang dilakukan oleh Fischbach, Harris, Ballan, Fischbach dan Link (2016) terhadap 502 orang tua yang direkrut dari Simons Simplex Collection, dan 60 ilmuwan peneliti yang direkrut dari peneliti yang didanai oleh Simons Foundation, ditemukan bahwa orang tua dan para ilmuwan berbeda secara signifikan mengenai keyakinan dari kemungkinan penyebab utama autism. Para ilmuwan percaya penyebab genetik sementara banyak orang tua percaya vaksin sebagai penyebab autisme. Dan temuan akhirnya adalah kesepemahaman bahwa komunikasi harus terjalin lebih baik antara orang tua dan para ilmuwan sehingga kesehatan dan kesejahteraan anak-anak dengan ASD bisa meningkat.

Hal yang paling penting adalah individu autis memiliki potensi untuk tumbuh dan berkembang. Autisme tidak dapat diobati. Ini penting bagi orangtua untuk memberikan layanan yang efektif, perawatan dan pendidikan bagi anak-anak autis mereka sesegera mungkin. Lebih cepat anak-anak ini menerima pengobatan yang tepat, lebih baik prognosis mereka. Meskipun perkembangan kemampuan anak autis lebih lambat daripada yang lain, tapi mereka masih bisa hidup bahagia dan produktif (Adam, Edelson, Grandin, \& Rimland, 2012).

Selama beberapa dekade terakhir, penelitian neurosains telah banyak dikembangkan dalam bidang kesehatan dan pemahaman psikologis tentang cara otak berkembang dan berfungsi. Studi pencitraan neurologis telah mengidentifikasi daerah otak yang terhubung ke fisik, psikologis, dan proses pembelajaran. Maka lingkup neurosains menjadi salah satu alternatif pengobatan fisik dan psikologis seseorang (Spaulding, Mostert, \& Beam, 2010).

Psychiatric and neurological disorders memperkenalkan fungsi "otak sosial". Gangguan perilaku seperti pada anak autis, adalah akibat dari tidak berfungsinya bagian otak sosial individu dan berpengaruh pula pada otak kognitif dan berakhir pada perilaku sosial individu (Kennedy \& Adolphs, 2012). Maka pemulihan bagian otak sosial yang tidak berfungsi baik pada anak autis ini perlu dilakukan secara komprehensif.

Mengaktifkan sensasi dalam tubuh seseorang termasuk anak autis perlu keadaan yang rileks dan suasana yang menyenangkan, karena dalam keadaan tegang seseorang tidak akan dapat menggunakan otaknya dengan maksimal karena pikiran menjadi kosong (Denisson, 2006). Suasana menyenangkan dalam hal ini berarti anak berada dalam keadaan yang sangat rileks, tidak ada sama sekali ketegangan yang mengancam dirinya baik fisik maupun non fisik (Papalia \& Olds, 2008). Keadaan tersebut akan memberikan kenyamanan tersendiri bagi anak untuk mengembangkan kemampuan kognitif dan membuka jalan bagi anak dalam mendayagunakan seluruh potensi yang dimilikinya. Pengembangan kognitif yang dimaksudkan yaitu individu mampu mengembangkan kemampuan persepsi, atensi, ingatan (memory), berpikir, konsentrasi, fokus-pemahaman terhadap simbol, melakukan penalaran dan memecahkan masalah (Santrock, 2006). Dalam studi ini yang akan diteliti adalah ingatan jangka pendek yang menjadi bagian dari kemampuan kognitif individu. Kemampuan kognitif berpusat pada organ otak individu, 
sehingga untuk meningkatkan kemampuan kognitif seseorang bisa dengan mengaktifkan fungsi otak.

ASD adalah gangguan perkembangan saraf yang memengaruhi hampir satu dari 88 anak-anak, yang diduga akibat penyimpangan konektivitas otak. Penelitian menggunakan neuroimaging menunjukkan bahwa lebih banyak konektivitas fungsional pada otak anak-anak dengan ASD dibandingkan dengan anak pada umumnya. Hyperconnectivity di ASD ditemukan ada pada tingkat seluruh-otak dan subsistem. Anak-anak dengan konektivitas fungsional yang lebih besar menunjukkan defisit sosial yang lebih parah, seperti kekhasan yang ada pada anak-anak dengan ASD ini yaitu ketidakmampuan dalam sosialisasi (Supekar, Uddin, Khouzam, Phillips, Gaillard, Kenworthy, Yerys, Vaidya, \& Menon, 2013).

ASD ditandai dengan gangguan sosialisasi bersama dengan kekakuan kognitif dan perilaku. Dilakukan penelitian terhadap dua kelompok partisipan, 17 anak-anak dengan ASD dan 17 anak dengan IQ standard. Pertama, dalam kondisi otak terstimulasi melalui aktivitas yang membutuhkan perhatian sosial dan sejumlah penyelesaian tugas, kedua, dalam keadaan otak istirahat. Kedua kelompok diperiksa mengenai kemampuan algoritma, hasilnya, konfigurasi fungsional jaringan otak pada kondisi perlakuan pertama, lebih akurat ada pada anak-anak normal dibandingkan anakanak dengan ASD. Terdapat discriminability keadaan otak anak yang terkait dengan keparahan ASD, dan ini menunjukkan bahwa lemahnya kemampuan otak dapat berkontribusi terhadap infleksibilitas perilaku sosial ASD (Uddin, Supekar, Lynch, Cheng, Odriozola, Barth, Phillips, Feinstein, Abrams, \& Menon, 2014).
Sebuah tes memori klinis diberikan kepada 38 anak dengan autisme dan 38 kontrol anak normal, usia 8-16 tahun. Profil yang dihasilkan dari kemampuan memori pada anak-anak dengan autisme ditandai dengan memori yang relatif miskin untuk informasi visual dan verbal kompleks dan memori kerja spasial. Sebuah analisis komponen utama menunjukkan bahwa struktur kognitif partisipan berbeda secara substansial antara anak autis dan kelompok kontrol, menunjukkan organisasi berbeda dari kemampuan memori (Williams, Goldstein, \& Minshew, 2006).

Salah satu upaya untuk mengaktifkan dan menyeimbangkan semua dimensi otak bisa dilakukan dengan senam otak atau brain gym (Dennison \& Dennison, 2005). Gerakan senam otak sangat sederhana, karena tidak seperti senam badan yang menekankan pada otot dan kebugaran. Senam otak bisa dilakukan dalam waktu singkat (kurang dari lima menit), tidak memerlukan bahan atau tempat khusus, memungkinkan belajar tanpa stres, meningkatkan kepercayaan diri, memandirikan seseorang dalam hal belajar, mengaktifkan potensi dan ketrampilan, menyenangkan dan menyehatkan, serta hasilnya bisa segera dirasakan (Demuth, 2008).

Penelitian di Jerman membuktikan bahwa Dennison menyusun ulang pola lateral otak Dennison Laterality Repatterning (DLR) sehingga dapat memperbaiki kemampuan membaca, daya ingat, dan bahasa. Tujuan proses gerakan DLR ini adalah untuk membantu individu menyeberangi batas tengah visuall auditory/kinestetik dalam proses bilateral (Donczik, 2001).

Senam otak lebih menitikberatkan pada gerakan yang dapat merangsang dan memadukan semua bagian otak, baik otak kiri maupun otak kanan (dimensi late- 
ralisasi), otak tengah (limbik), otak depan (dimensi pemfokusan) maupun otak besar (dimensi pemusatan). (Merangsang Otak Anak dengan Brain Gym, 2007). Diharapkan melalui rangkaian gerakan tubuh, dapat menarik keluar kemampuan kognitif anak. Senam otak juga dikenal sebagai jalan keluar bagi bagian-bagian otak yang "terhambat" agar dapat berfungsi maksimal. Selain itu senam otak juga dapat meningkatkan kemampuan berbahasa dan daya ingat. Orang menjadi lebih bersemangat, lebih konsentrasi, lebih kreatif dan efisien. Siapapun akan merasa lebih sehat karena stres berkurang (Tammasse, 2011). Pada Klinik Neurologi dan Rehabilitasi Medis dan Geriatrics di Henriettenstiftung, di wilayah Hanover Jerman, kelompok pasien dengan penyakit Alzheimer dibuat kegiatan pelatihan senam otak untuk meningkatkan fungsi otak serta untuk meningkatkan kesadaran tubuh. Dari 24 partisipan tes dalam penelitian ini, 16 menunjukkan kinerja yang lebih baik setelah melakukan Brain Gym (Thiemann, Hedwig, Kenklies, Blomberg, Marahrens, Marahrens, \& Hager, 2002).

Dalam sebuah studi selama delapan minggu mengenai pengaruh Brain Gym terhadap kemampuan membaca dan pemahaman, dengan partisipan anak sekolah 18 delapan tahun dengan kesulitan membaca dibagi menjadi tiga kelompok secara acak dari enam masing-masing siswa: kelompok bermain (gerakan bebas), sebuah kelompok psikomotor (gerakan tradisional), dan kelompok gerakan Brain Gym. Setiap kelompok melakukan 15 menit setiap hari. Kelompok Gerakan Brain Gym melakukan empat PACE gerakan (Air, Buttons Brain, Palang Crawl, $\mathcal{E}$ Hook-up) bersama dengan Tombol Bumi, Tombol Angkasa, dan Dennison lateralitas Repatterning. Setiap minggu, mahasiswa dari Universitas Gie Ben memeriksa semua kelompok dalam kemahiran membaca. Sebuah analisis statistik doubleblind data menunjukkan bahwa anak-anak yang telah melakukan Brain Gym lebih cepat dalam kegiatan membaca, dengan sedikit kesalahan, dan lebih baik dalam pemahaman materi teks daripada dua kelompok pembanding lainnya (Beigel, Steinbauer, \& Zinke, 2002).

Berdasarkan riset yang dilakukan oleh Ayinosa pada tahun 2008, senam otak dapat memberikan pengaruh positif pada peningkatan konsentrasi, atensi, kewaspadaan dan kemampuan fungsi otak untuk melakukan perencanaan, respons dan membuat keputusan. Gerakan-gerakan dalam senam otak digunakan oleh para murid di Educational Kinesiology Foundation, California, USA untuk meningkatkan kemampuan belajar mereka dengan menggunakan keseluruhan otak (Lestarin, 2009).

Seluruh kemampuan manusia berada pada pusat kendali organ otak. Pada anak dengan ASD, terdapat hambatan dalam tiga area psikologis, yaitu komunikasi, interaksi sosial, dan perilaku, dan ketiga area tersebut berada dalam kemampuan kognitif secara umum yang berpusat pada organ otak. Salah satu kemampuan kognitif adalah daya ingat atau memori, dan pada anak dengan ASD ini, memori jangka pendek tidak berjalan dengan mudah, diperlukan stimulus yang menarik untuk menjadikan anak dengan ASD mampu fokus-atensi, sehingga bisa berkonsentrasi. Senam otak adalah suatu teknik senam sederhana yang dapat bermanfaat untuk mengaktifkan dan menyeimbangkan semua dimensi otak, sehingga dapat berfungsi optimal. Penelitian ini bertujuan untuk melihat pengaruh terapi senam otak terhadap kemampuan memori jangka pendek anak autis. 


\section{Metode}

Penelitian menggunakan metode eksperimen kuasi, dengan variabel bebas yaitu terapi senam otak, dan variabel tergantung yaitu memori jangka pendek. Pengukuran terhadap memori jangka pendek menggunakan Digit Span Form dari Weschler (1997).

Penelitian dilakukan di SLB ' $N$ ' Semarang. Populasi siswa autis di SLB N Semarang sebanyak 25 anak. Dengan menggunakan purposive sampling, dan membatasi karakteristik sampel partisipan dengan low spectrum autism, yaitu anakanak ASD dengan gejala autis ringan, agar mampu mengikuti instruksi sederhana gerakan senam otak, maka diperoleh jumlah partisipan 10 orang.

Treatment senam otak diberikan berupa paket media (musik, VCD, modul, gambar), dilengkapi dengan menyediakan air putih, alat tulis, dan alat permainan.

Penelitian ini menggunakan metode quasi experimental design, dengan the one group pretest-posttest design, yaitu tanpa menggunakan control group, mengingat keterbatasan lokasi, waktu dan jumlah partisipan sesuai kriteria.

\section{Prosedur penelitian}

1) Sebelum dilakukan roleplay, orang tua partisipan diberi penjelasan dan diminta kesediaannya untuk menandatangani informed consent bagi anaknya untuk menjadi partisipan penelitian.

2) Roleplay (uji coba) Senam Otak dilakukan terhadap partisipan, kemudian ditetapkan gerakan senam otak yang sesuai kemampuan anak autis yaitu sejumlah 12 gerakan dari total 23 gerakan senam otak. Gerakan tersebut adalah cross, hooks up, lazzy 8, putaran leher, mengaktifkan tangan, burung manguni, luncuran gravitasi, sakelar otak, tombol bumi, menguap berenergi, pasang telinga, dan titik positif.

3) Kepada partisipan penelitian yaitu sebanyak 10 anak autis di SLB ' $N$ ' Semarang diberikan pre-test, yaitu untuk mengukur kemampuan memori jangka pendeknya.

4) Kepada partisipan penelitian dilakukan terapi senam otak, yaitu sebanyak dua kali seminggu, selama 15 menit, maka total adalah 10 kali senam otak yaitu selama lima minggu.

5) Terakhir dilakukan post-test materi yang serupa, dan diukur perubahan skor yang terjadi.

6) Metode dalam treatment dan evaluasi (pre-post test) adalah Individualized Education Programme (IEP), karena kemampuan anak autis berbeda dengan perbedaan yang tidak sesuai usia kronologis.

\section{Analisis Data}

Penelitian ini menggunakan teknik analisis data non-parametik yaitu Wilcoxon Test, merupakan uji beda antara pre-test dan post-test untuk dua sampel dependen.

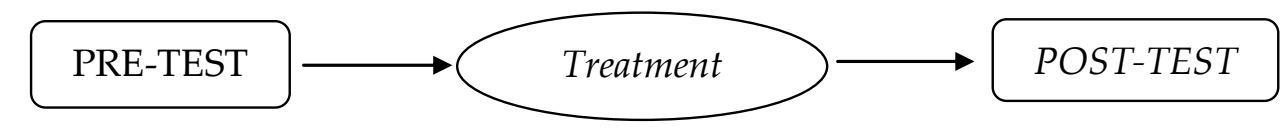

Gambar 1. Desain Penelitian 


\section{H a $s$ i 1}

Tabel 1

Nilai Z pada Skor Total Test Statistics

\begin{tabular}{cc}
\hline & $\begin{array}{c}\text { postes total - } \\
\text { pretes total }\end{array}$ \\
\hline$Z$ & $-2.023^{a}$ \\
Asymp. Sig. (2-tailed) & .043 \\
\hline
\end{tabular}

a. Based on negative ranks

b. Wilcoxon Signed Ranks Test

Hasil uji Wilcoxon pada Short Term Memory Test menunjukkan bahwa terdapat perbedaan yang signifikan antara skor pretest dan post-test. Nilai perbedaan ditunjukkan dari nilai $z=-2.023$ dengan taraf signifikansi 0,043<0,05 berarti bahwa ada perbedaan rerata hasil pre-test dan posttest, dengan peningkatan pada skor posttest.

Tabel 2

Statistik Deskriptif Sort Term Memory

Descriptive Statistics

\begin{tabular}{lccccc}
\hline & & \multicolumn{5}{c}{ Std. } \\
& $\mathrm{N}$ & Mean & Deviation & Min. & Max. \\
\hline Pretest & 10 & 6.6000 & 1.34164 & 6.00 & 9.00 \\
Posttest & 10 & 11.4000 & 2.50998 & 9.00 & 15.00 \\
\hline
\end{tabular}

Tabel 2 menunjukkan bahwa terdapat peningkatan rata-rata skor post-tes pada kesepuluh partisipan, yang tampak dari skor minimum dan maksimum.

\section{Diskusi}

Autisme adalah gangguan perkembangan yang ditandai dengan gangguan dalam komunikasi, interaksi sosial, dan perilaku. Hasil asesmen terhadap 10 anak autis dengan Low Spectrum Autism di SLB ' $N$ ' Semarang, menunjukkan bahwa partisipan memiliki keterbatasan dalam hal: menyusun bahasa dalam komunikasi, hambatan dalam eskpresi emosi sehingga sering menunjukkan amarah berlebihan, rendahnya kemandirian, dan perilaku repetitif.

Hasil analisis data terhadap skor pretest dan post-test pada Short Term Memory Test dengan Wilcoxon Test yang tampak pada tabel 1, menunjukkan bahwa terdapat peningkatan skor pada post-test, yaitu dengan nilai $Z=-2,023$ dan taraf signifikansi $0,043<0,05$ yang berarti meningkat secara signifikan, dengan data deskriptif pada Tabel 2. Treatment berupa senam otak diberikan dua kali seminggu dengan total selama 10 kali. Peningkatan skor post-test ini menandakan bahwa treatment yang diberikan berupa rangkaian gerakan senam otak kepada partisipan 10 anak autis, memberikan pengaruh terhadap peningkatan kemampuan memori jangka pendek anak.

Meskipun gangguan spektrum autisme dikenal dengan gangguan-komunikasi sosial, hasil studi telah menemukan bahwa kinerja tes kognisi sosial juga turut berubah. Suatu penelitian menguji kemampuan sosial kognitif secara eksplisit (diminta) dan implisit (spontan) pada ASD. Sampel terdiri dari 19 remaja dengan ASD dan 19 remaja yang mampu menyelesaikan Dewey Story Test. Pada partisipan ASD menunjukkan hasil tidak berbeda dengan kelompok kontrol mengenai kinerja kognisi sosial eksplisit. Namun, kelompok ASD menunjukkan hasil lebih rendah daripada kelompok kontrol pada kinerja kognisi sosial implisit dalam hal mengambil perspektif spontan dan kesadaran sosial (Callenmark, Kjellin, Rönnqvist \& Bölte, 2013). Suatu penelitian lain dengan tujuan untuk melihat perubahan perilaku hasil intervensi latihan untuk individu dengan ASD yang berusia 
kurang dari 16 tahun menunjukkan hasil bahwa intervensi latihan individual yang terdiri dari jogging, menunggang kuda, seni bela diri, berenang atau yoga/tari dapat menghasilkan perbaikan dalam berbagai perilaku individu termasuk perilaku stereotipik, fungsi sosial-emosional, kognisi dan perhatian (Bremer, Crozier, \& Lloyd, 2016).

Kemampuan kognitif untuk anak dengan ASD (Desiningrum, 2016) dan melalui temuan hasil penelitian ini, adalah:

- Anak dengan ASD mempunyai daya ingat yang sangat kuat terutama yang berkaitan dengan objek visual (gambar), dan ingatannya cenderung membutuhkan pengulangan lebih banyak sehingga masuk ke dalam long term memory.

- Anak dengan ASD memiliki kemampuan lebih pada bidang yang berkaitan dengan angka.

Hasil penelitian ini menunjukkan adanya pengaruh treatment senam otak yang dilakukan selama 10 kali terhadap kemampuan memori jangka pendek pada partisipan. Hal ini sesuai dengan hasil penelitian yang dilakukan oleh Demuth (2007) yang menemukan bahwa senam otak dapat membuka bagian otak yang sebelumnya tertutup atau terhambat sehingga kegiatan belajar berlangsung baik karena seluruh bagian otak dipakai. Senam otak adalah serangkaian latihan gerak sederhana yang memudahkan kegiatan belajar dan penyesuaian dengan tuntutan sehari-hari. Artikel lain menyebutkan bahwa meskipun brain gym pernah dikritik oleh ilmuwan syaraf, guruguru terus mendukung dan memfasilitasi penerapan senam otak di sekolah-sekolah Australia, karena cukup dirasa menstimulasi otak dan koordinasi tubuh secara umum (Stephenson, 2009).
Otak terdiri atas dua belahan, yaitu kanan dan kiri yang fungsinya berbeda namun saling mendukung. Otak kiri sering dikaitkan dengan akademis (matematika, menulis, dan membaca), fungsi verbal, temporal, logis, analitis, rasional serta kegiatan berpola. Otak kanan lebih pada nonakademis, seperti seni, pemahaman ruang, dan bentuk kegiatan yang memancing kreativitas. Otak anak bisa dilatih melalui aktivitas motorik seperti senam otak ini. Dalam suatu artikel penelitian disebutkan bahwa bentuk olahraga dan latihan bisa menjadi cara sederhana untuk menjaga fungsi otak dan meningkatkan plastisitas otak (Cotman \& Berchtold, 2002).

Dampak senam otak dapat membantu membangun kepercayaan diri serta berpengaruh positif dalam menambah konsentrasi, meningkatkan fokus, daya ingat, dan mengendalikan emosi anak (Lestarin, 2009).

Melalui hasil observasi ketika dilaksanakan treatment, anak-anak autis pada dasarnya menyukai aktivitas fisik seperti senam otak ini. Khususnya untuk ASD dengan low chategory, yang tidak disertai hiperaktivitas. Pada awalnya dibutuhkan pendekatan yang baik, melalui pengenalan gerakan-gerakan senam otak ini, yang membutuhkan waktu kurang lebih dua kali pertemuan sebelum masuk pada treatment senam otak. Temuan dalam penelitian ini, yaitu adanya atensi atau perhatian anak terhadap instruktur senam otak, yang terus meningkat seiring dengan tahapan treatment. Diantaranya yaitu anak mau memberikan perhatian saat mengerjakan aktivitas tertentu seperti menulis, menggambar termasuk mela-kukan senam otak, meskipun ada gangguan berupa suasana ramai di luar ruangan dan suara musik. 
Peningkatan kemampuan memori yang tampak dari seluruh partisipan, selain terukur jelas pada digit span test, juga tampak dari hasil observasi peneliti. Ada tiga partisipan yang mampu mengulang langsung dalam menyebut dengan benar nama benda baru yang dibawa oleh peneliti, yaitu tip ex, stetoskop mainan, mobil box mainan, piano mainan, dan kompor mainan, pada pertemuan/ treatment yang kesembilan.

Hasil penelitian Fajriananda, Siregar, dan Aslamiyah (2009) menunjukkan bahwa puzzle khususnya APE Puzzle, merupakan permainan yang dapat menarik minat anak untuk memainkannya dan memberi pengalaman yang baik bagi kecerdasan anak bila dirangsang dan diarahkan oleh tenaga pendidik dengan dukungan yang tepat dan sesuai tujuan. Pada penelitian ini senam otak menjadi salah satu media terapi yang ringan dan menarik bagi anak, sehingga mampu meningkatkan secara signifikan kemampuan memori anak, termasuk anak autis.

Disebutkan di awal pembahasan ini bahwa sebagian kecil individu autis mempunyai daya ingat yang sangat kuat terutama yang berkaitan dengan objek visual (gambar), dan ingatannya cenderung membutuhkan pengulangan lebih banyak agar bisa masuk ke dalam long term memory. Senam otak yang dilakukan untuk meningkatkan kemampuan memori anak autis ini lebih ditujukan pada short term memory. Hasil penelitian, ketika pre-test dengan digit span, semua partisipan rata-rata hanya mampu mengingat dua digit angka, dan pada saat post-test, meningkat menjadi dapat mengulang 3-5 digit angka. Pada anak normal usia 6-12 tahun, ingatan jangka pendek bisa berada pada skor pengulangan 6-8 angka. Pada anak autis terdapat kendala yaitu kurang mampu menangkap informasi cepat dari pendengaran yang tidak diikuti visual, sehingga tidak mampu mengulang langsung setelah mendengarkannya. Setelah melalui terapi senam otak, maka kemampuan memori jangka pendek anak autis meningkat.

Penelitian ini menggunakan quasi experimental design, dengan the one group pre-test-post-test design, mengingat keterbatasan lokasi, waktu dan jumlah partisipan sesuai kriteria. Maka hal ini menjadi suatu kelemahan, karena merupakan penelitian eksperimen tanpa menggunakan control group dan random assignment. Penelitian eksperimen tanpa random assignment kelemahannya adalah tidak adanya homogenitas partisipan, sehingga tidak bisa memastikan bahwa perbedaan skor pre dan posttest adalah akibat dari treatment senam otak. Demikian pula tidak adanya control group, meskipun perbedaan kedua hasil pengukuran pre dan post-test dianggap sebagai efek perlakuan, validitas penelitian ini masih lemah karena hanya sedikit sumber invaliditas yang diketahui dan dikendalikan. Sumber validitas yang tidak dikendalikan antara lain drop out partisipan, seleksi diferensial, historis, kematangan (Shadis, Cook, \& Campbel, 2002). Maka, perbedaan yang muncul pada hasil pre-test dan post-test kemungkinan dari faktor lain, seperti perbedaan kemampuan intelektual pada anak autis karena kesulitan dalam pengukurannya.

Terdapat temuan lain dalam penelitian ini yaitu setelah dilakukan uji coba senam otak terhadap partisipan, disimpulkan bahwa tidak semua gerakan senam otak mampu diikuti secara sempurna oleh anak dengan gangguan autis. Sejumlah gerakan yang ditetapkan dalam penelitian ini yaitu sejumlah 12 gerakan dari total 23 gerakan senam otak menurut Dennison (2006). Gerakan tersebut adalah cross, hooks up, lazzy 8, putaran leher, mengaktifkan 
tangan, burung manguni, luncuran gravitasi, sakelar otak, tombol bumi, menguap berenergi, pasang telinga, dan titik positif.

Penelitian ini juga menemukan bahwa senam otak dengan gerakan-gerakan yang sederhana, mudah dan singkat ini, tidak dirasakan demikian bagi anak-anak autis yang masih merasa kesukaran dalam mengikutinya. Dalam pelaksanaannyapun suasana hati (mood) dan kemampuan anak autis berbeda satu sama lain, sehingga partisipan memiliki perbedaan kualitas dalam hal mengikuti gerakan senam otak secara optimal, maka peneliti meminimalisir kendala ini dengan metode Individualized Education Programme (IEP), yaitu treatment dilakukan secara individu dengan dilengkapi data observasi lengkap.

\section{Kesimpulan}

Senam otak dapat dijadikan salah satu alternatif terapi bagi anak ASD dengan low chategory tanpa gangguan hiperaktivitas. Hal ini dapat dilihat dari hasil penelitian yang menunjukkan bahwa terdapat perbedaan skor pada pre-test dan post-test yang meningkat cukup signifikan pada kemampuan memori jangka pendek, meski terdapat kelemahan yaitu tidak adanya control group dan random assignment pada desain penelitian. Dari penelitian ini ditemukan juga bahwa adaptasi pada anak-anak autis membutuhkan waktu yang lebih panjang dibandingkan dengan anak pada umumnya. Penelitian menemukan model terapi senam otak yang sesuai untuk anak autis sebagai salah satu upaya meningkatkan kemampuan memori jangka pendek pada anak autis yaitu hanya 12 gerakan dari total 23 gerakan senam otak menurut Dennison (2006). Treatment dilakukan secara individu yaitu melalui pendekatan IEP.
Saran

Peneliti lain dapat mencoba untuk melihat pengaruh senam otak terhadap kemampuan komunikasi, interaksi sosial, dan perilaku, yang menjadi kendala pada anak autis pada umumnya, agar sesuai dengan kebutuhan anak autis itu sendiri. Agar hasilnya dapat lebih signifikan, maka partisipan bisa dikembangkan dalam hal jumlah dan usia, dengan tetap menggunakan IEP mengingat keunikan pada anak autis.

\section{Kepustakaan}

Adam J. B., Edelson, S. M., Grandin, T., \& Rimland, B. (2012). Advice for parents of young autistic children. Autism Research Institute, 5(6), 99-108. Diunduh dari: https://www.autism. com/understanding_advice.

Barbeau, E. B., Meilleur, A. S., Zeffiro, T. A., \& Mottro, L. (2015) Comparing motor skills in autism spectrum individuals with and without speech delay. Autism Research Journal, 8(6), 682-693. http://dx.doi.org/10.1002/ aur.1483.

Beigel, D., Steinbauer, W., \& Zinke, K. (2002) The effects of Brain Gym ${ }^{\circledR}$ on reading and comprehension. $V A K$ Verlags GmbH Kirchzarten bei Freiburg. V. 43-79.

Budhiman, M., Shattock, P., \& Ariani, E. (2002). Langkah awal menanggulangi autisme dengan memperbaiki metabolisme tubuh. Jakarta: Nirmala.

Bremer, E., Crozier, M., \& Lloyd, M. (2016) A systematic review of the behavioural outcomes following exercise interventions for children and youth with autism spectrum disorder. Autism. http://dx.doi.org/10.1177/13623 61315616002 


\section{DESININGRUM}

Callenmark, B., Kjellin, L., Rönnqvist, L., \& Bölte, S. (2013) Explicit versus implicit social cognition testing in autism spectrum disorder. Autism. http://dx. doi.org/10.1177/1362361313492393

Cotman, C. W., \& Berchtold, N. C. (2002). Exercise: A behavioral intervention to enhance brain health and plasticity. Trends Neuroscience, 25(6), 295-301. http://www.ncbi.nlm.nih.gov/pubmed /12086747

Crane, L, Chester, J. W, Goddard, L., Henry, L. A., \& Hill, E. (2015) Experiences of autism diagnosis: A survey of over 1000 parents in the United Kingdom. http://dx.doi.org/ 10.1177/1362361315573636

Data Autis di Indonesia, Diunduh dari: http://autismindonesia.org/ tanggal 9 Maret 2014.

Demuth, E. (2007). Brain gym for all: From pre-birth to old age. Brain Gym ${ }^{\circledR}$ Journal , XXII(1),

Demuth, E. (2008). Brain gym, pedoman senam otak bagi guru dan peminat, Sulawesi Utara: Yayasan Kinesiology Indonesia.

Dennison. (2006). Brain gym. Jakarta: PT Gramedia.

Dennison, P. E., \& Dennison, G. E. (2005). Brain gym. Jakarta: PT Grasindo.

Desiningrum, D. R. (2016). Pengantar psikologi anak berkebutuhan khusus. Jakarta: Graha Ilmu.

Donczik, J. (2001). Edited Englishlanguage translation by Christine M. Grimm and Sigrid Wong, republished in the Brain Gym ${ }^{\circledR}$ Journal, XV(1-2), from "Konnen edukinestetische Ubungen (Brain-Gym ${ }^{\circledR}$ ) Legasthenikern helfen?" in Die Sprach-heilarbeit 39
(1994), S. 297-305, a German Publication.

Fajriananda, Siregar, Y., \& Aslamiyah S. (2009). Efektifitas alat permainan edukatif produksi BPPLSP regional I dalam peningkatan multiple intelligence anak usia dini. Jurnal Pendidikan, II, 86-104.

Fischbach, R. L., Harris, M. J., Ballan, M. S., Fischbach, G, D., \& Link, B. G. (2016). Is there concordance in attitudes and beliefs between parents and scientists about autism spectrum disorder? Autism. 20(3) 353-363. http://dx.doi. org/10.1177/1362361315585310

Kennedy, D. P., \& Adolphs, R. (2012). The social brain in psychiatric and neurological disorders. Trends in Cognitive Sciences, 16(11), 559-572. http://dx.doi.org/10.1016/j.tics.2012.09. 006

Lestarin, R. D. (2009). Pengaruh senam otak (brain gym) terhadap kualitas komunikasi, interaksi sosial dan pemfokusan pemahaman pada anak di yogyakarta. Yogyakarta: Program PKMP, UMY.

Merangsang Otak Anak Dengan Brain Gym. (2007). Diunduh dari: http:// salamsehat.com/merangsang-otakanak-dengan-brain-gym.php. Juni 2013.

NINDS (Autism Information Page), (2006). National institute of neurological disorders and stroke (NINDS). Retrived from: http://www.ninds. nih.gov/disorders/autism/autism.htm \#What_is (accessed: 2013, Oktober 01)

Papalia, D. E., \& Olds, S. W. (2008). Human development. (9th ed). New York: Mc Graw Hill Companies. 
Santrock, J. W. (2006). Psychology (8th ed.). New York: McGraw Hill.

Schechter, R. I., \& Grether, J. K. (2008). Continuing increases in autism reported to California's developmental services system: Mercury in retrograde, 65(1), 19-24. Diunduh dari: http://www.ncbi.nlm.nih.gov/pubmed /18180424.

Shadish, W. R., Cook, T. D., \& Campbell, D. T. (2002). Experimental and quasiexperimental designs for generalized causal inference. Boston, MA: Houghton Mifflin.

Spaulding, L. S., Mostert, M. P., \& Beam, A. (2010). Is brain gym an effective educational intervention?. Faculty Publications and Presentations. Paper 148. Diunduh dari: http:// digitalcommons.liberty.edu/educ_fac_ pubs/148

Stephenson, J. (2009). Best practice? Advice provided to teachers about the use of brain $\operatorname{gym}^{\circledR}$ in australian schools. Australian Journal of Education, 53(2), 109-124. http://dx.doi.org/ 10.1177/000494410905300202.

Supekar, K., Uddin, L. Q., Khouzam, A., Phillips, J., Gaillard, W. D., Kenworthy, L. E., Yerys, B E., Vaidya,
C. J., \& Menon, V. (2013). Brain hyperconnectivity in children with autism and its links to social deficits. Cell Reports, 5(3), 738-747. http://dx. doi.org/10.1016/j.celrep.2013.10.001

Tammasse, J. (2009). Lakukan senam otak. Harian Fajar. Edisi 19 Juli 2011.

Thiemann, G. D., Hedwig, D., Kenklies, M., Blomberg, A.V., Marahrens, G., Marahrens, A., \& Hager, K. (2002). The effect of brain gym on the cognitive performance of alzheimer's patients. Brain Gym® Journal, XVI(1).

Uddin, L. Q, Supekar, K., Lynch, C. J, Cheng, K. M., Odriozola, P., Barth, M.E, Phillips, J., Feinstein, C., Abrams D. A., \& Menon, V. (2014). Brain state differentiation and behavioral inflexibility in autism. Cerebral Cortex Advance. Diunduh dari: http:// cercor.oxfordjournals.org/content/earl y/2014/07/22/cercor.bhu161.short

Wechsler, D. (1997). Wechsler adult intelligence scale - Third edition. San Antonio, TX.

Williams, D. L., Goldstein, G., \& Minshew, N. J. (2006). The profile of memory function in children with autism. Neuropsychology, 20(1), 21-29. http:// dx.doi.org/10.1037/0894-4105.20.1.21 